\title{
Application of central composite designs in the supercritical fluid extraction of tropane alkaloids in plant extracts ${ }^{1}$
}

\author{
A. Brachet ${ }^{2}$, L. Mateus ${ }^{2}$, S. Cherkaoui ${ }^{2}$, P. Christen², J.-Y. Gauvrit ${ }^{3}$, P. Lantéri ${ }^{3}$, J.-L. Veuthey² ${ }^{2}$ \\ ${ }^{2}$ University of Geneva, Laboratory of Pharmaceutical Analytical Chemistry, \\ 20 boulevard d'Yvoy, CH-1211 Geneva 4, Switzerland \\ ${ }^{3}$ University of Lyon, ESCPE Lyon, Laboratory of Chemometrics, 43 boulevard du 11 novembre 1918, \\ 69622 Villeurbanne, France
}

\begin{abstract}
Central composite designs were used in the study of supercritical fluid extraction (SFE) of three tropane alkaloids : hyoscyamine and scopolamine from Datura candida x D. aurea hairy roots and cocaine from coca leaves (Erythroxylum coca). Several SFE parameters, such as pressure, temperature, the nature and percentage of the polar modifier were examined. The tropane alkaloid extraction yield was established as response. A comparison between the predicted and the experimental extraction yields was established in order to assess the prediction quality of the model. Response surfaces were drawn from the mathematical models and enabled to determine the optimal conditions and to visualise the method robustness. The behaviour of the compounds investigated was discussed in relation with the selected SFE parameters.
\end{abstract}

Key words. Supercritical fluid extraction - experimental design - hyoscyamine - scopolamine - cocaine - plant extract.

\section{Introduction}

Screening designs are mainly used to estimate the effects of factors in experimental studies on a statistical basis [1]. Two main designs can be selected according to the number of factors. As long as this number is small, full factorial designs can be used but, in the case of multiple factors, Plackett and Burman designs should be preferred [2]. Whereas the latter allow only estimating main effects, full factorial designs enable to determine the most relevant factors and their influence range as well as the factor's interactions. However, both present a major limitation as they are first-degree factorial design, which implies that the estimated variables are linear over the whole range of experimentation. Second-degree designs such as central composite [1], Doelhert designs [3] allow to model non-linear variables and determine optimal conditions $[4,5]$. The prediction quality of the model is verified by the good agreement between the experimental and predicted responses. Furthermore, the central composite design offers the possibility to evaluate the method robustness by drawing response surfaces [6].

For centuries, plants have been the unique source of therapeutically significant drugs such as alkaloids. Among them, tropane alkaloids represent an important class of therapeutic compounds, such as hyoscyamine, scopolamine and cocaine. Hyoscyamine, its racemate atropine and scopolamine, are extensively used in ophthalmic diagnosis as mydriatic as well as anticholinergic, antispasmodic and preanesthesic agents [7]. Cocaine is well known as a topical anaesthetic and vasoconstrictor and for its stimulant action on the central nervous system [8]. The chemical structure of these compounds is shown in figure 1 .

Supercritical fluid extraction (SFE) has become the method of choice for the extraction of secondary metabolites from solid matrices such as plant material $[9,10]$. It represents an interesting alternative technique to conventional liquid-solid extraction (e.g. Soxhlet extraction), with lower solvent consumption and working temperature. In addition, SFE offers other advantages related to the favorable properties of supercritical fluids: the low viscosity and high solute diffusivity improve the mass transfer and reduce the extraction time [11, 12]. Moreover, selecting the fluid polarity and/or density allows to adjust the solvating power of the fluid which enables class-selective extraction [13, 14].

Analysis of cocaine by both capillary [15] and packed column [16] supercritical fluid chromatography (SFC) using neat $\mathrm{CO}_{2}$, showed a reasonable solubility of the compound which suggests that cocaine should be extracted by SFE. Furthermore, cocaine has already been extracted by SFE in hair samples [17, 18]. Stahl reported the difficulty of hyoscyamine and scopolamine extractions from Belladonnae folium with neat $\mathrm{CO}_{2}$ only [19].

In this paper, the feasibility of using a supercritical fluid modified with a polar solvent is demonstrated for the extrac-

1. This work was presented at the chromatographic symposium SEP'99 in Lyon (France), March 31-April 2, 1999.

*Correspondence and reprints.

Received July 23, 1999; revised September 9, 1999; accepted September 14, 1999. 


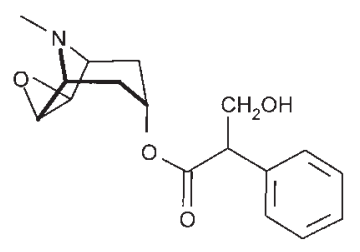

Scopolamine

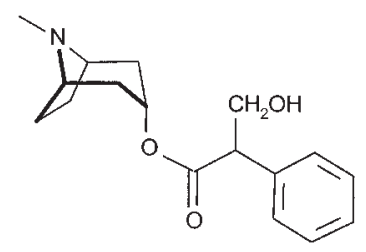

Hyoscyamine

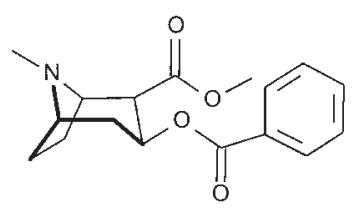

Cocaine

Fig 1. Structure of the investigated alkaloids.

tion of hyoscyamine, scopolamine from Datura candida $\mathrm{x}$ D. aurea hairy roots and of cocaine from Erythroxylum coca var. coca. Central composite designs were applied to optimise the selected SFE factors. For hyoscyamine and scopolamine extractions, all the results are reported, whereas for cocaine, the complete development was described elsewhere [20] and some results only are reported here. Hairy root extracts were analysed by micellar electrokinetic chromatography (MEKC), as already described [21]. Coca extracts were analysed by capillary GC-FID [20].

\section{Experimental}

\section{Reagents and materials}

Hyoscyamine sulfate and scopolamine hydrobromide were purchased from Sigma (St-Louis, MO, USA) and homatropine hydrobromide from Merck (Darmstadt, Germany). Cocaine hydrochloride and methadone hydrochloride were obtained from Siegfried Handel (Zofingen, Switzerland) and Hänseler (Herisau, Switzerland), respectively.

All chemicals were of analytical grade. Sodium dodecyl sulfate (SDS), sodium dihydrogen phosphate, sodium tetraborate, methanol $(\mathrm{MeOH})$ and acetonitrile $(\mathrm{MeCN})$ were obtained from Fluka (Buchs, Switzerland). Ultrapure water was provided by a Milli-Q RG unit from Millipore (Bedford, MA, USA). For supercritical fluid extraction, $99.99 \%$ purity $\mathrm{CO}_{2}$ (Polygaz, Geneva, Switzerland) contained in a cylinder with an eductor tube was used.

The culture of Datura candida x Datura aurea hairy roots was established after infection with Agrobacterium rhizo- genes $\mathrm{A}_{4}$ as already reported [22]. Leaves of E. coca var. coca were harvested in Tingo Maria in Peru. Leaves were authenticated by T. Plowman and were kindly provided by Dr L. Rivier from the Forensic Institute of Lausanne (Switzerland).

\section{Instrumentation}

\section{Supercritical Fluid Extraction (SFE)}

Powdered plant material was placed in an extraction cell $(1 \mathrm{ml}$ internal volume, $5.6 \mathrm{~cm}$ long $\times 0.5 \mathrm{~cm}$ I.D. $)$ supplied by Supelco (Bellefonte, PA, USA). $\mathrm{CO}_{2}$ and polar modifier were delivered by a Varian 2510 HPLC pump (Varian, Palo Alto, CA, USA) and a SSI 220 B HPLC pump (State College, USA), respectively. A six-way switching valve (Rheodyne, CA, USA) was used to by-pass the extraction cell which was placed in a home-made oven $\left(20-110^{\circ} \mathrm{C}\right)$. The pressure in the system was monitored by a back-pressure regulator JASCO, model 880-81 (JASCO, Tokyo, Japan) and the variable restrictor was heated at $40{ }^{\circ} \mathrm{C}$ for hyoscyamine and scopolamine and $70{ }^{\circ} \mathrm{C}$ for cocaine to avoid dry ice formation.

For cocaine extraction, the air-dried plant material was thoroughly ground in a domestic mixer to obtain a particle size distribution between 150 and $170 \mu \mathrm{m}$ and $100 \mathrm{mg}$ of this material was placed in the extraction cell. For hyoscyamine and scopolamine extractions, $50 \mathrm{mg}$ of powdered hairy roots $(<470 \mu \mathrm{m})$ were used. Each extraction was performed by filling the cell with the supercritical fluid before heating for 10 minutes at the temperature set by the experimental design. In a preliminary study (data not shown), kinetics were carried out in non-optimised conditions (i.e. $\mathrm{CO}_{2} / \mathrm{MeOH} / \mathrm{H}_{2} \mathrm{O}, 90 / 9 / 1 \mathrm{v} / \mathrm{v} / \mathrm{v}, 20 \mathrm{MPa}$ and $40{ }^{\circ} \mathrm{C}$ for cocaine; $\mathrm{CO}_{2} / \mathrm{MeOH}, 80 / 20 \mathrm{v} / \mathrm{v}, 20 \mathrm{MPa}$ and $70^{\circ} \mathrm{C}$ for hyoscyamine and scopolamine) in order to assess extraction times and flow rates for the complete extraction of compounds of interest. 10 minutes with a flow rate of $2 \mathrm{ml} / \mathrm{min}$ were sufficient to extract quantitatively cocaine [20], while 20 minutes with a flow rate of $1 \mathrm{ml} / \mathrm{min}$ were sufficient to extract completely hyoscyamine and scopolamine. Therefore, extraction time was set at $15 \mathrm{~min}$ for cocaine and $30 \mathrm{~min}$ for hyoscyamine and scopolamine, in order not to take into account the time as factor.

After extraction, the system was flushed with methanol for 5 minutes. All samples were collected by bubbling in $5 \mathrm{ml}$ methanol maintained at $5{ }^{\circ} \mathrm{C}$ in an ice bath in order to increase the collection efficiency of tropane alkaloids. Extracts were then evaporated to dryness under a gentle stream of nitrogen.

\section{Liquid-solid extraction}

Liquid-solid extraction of hyoscyamine and scopolamine from powdered Datura candida x Datura aurea hairy roots was carried out according to the procedure described elsewhere [23], while cocaine was extracted from coca leaves as reported in the literature [24]. 


\section{Original articles}

\section{Analysis}

The dry residue of hyoscyamine and scopolamine was redissolved in $500 \mu \mathrm{l}$ of an aqueous solution of homatropine (at a concentration of $100 \mu \mathrm{g} / \mathrm{ml}$ ) for analysis by micellar electrokinetic capillary chromatography [21]. For cocaine, the dry residue was redissolved in $2 \mathrm{ml}$ of a methanolic solution of methadone (at a concentration of $45 \mu \mathrm{g} / \mathrm{ml}$ ). The mixture was centrifuged at $1700 \mathrm{~g}$ for 5 minutes. Extracts were analysed without any further purification by GC-FID and the identification of the cocaine peak was confirmed by GC-MS, as described elsewhere [20].

\section{Software}

Coefficients for the regression models and the optimised conditions were calculated using NEMROD [4] and LUMIERE [5] software packages. Response surfaces were drawn with Microsoft Excel (version 7.0).

\section{Results and discussion}

\section{Selection of relevant SFE factors}

The supercritical fluid extraction of hyoscyamine, scopolamine and cocaine was optimised by the use of central composite designs. Extraction of such polar compounds was mainly governed by the solvating power of the fluid and therefore, pressure, temperature, the nature and percentage of the polar modifier were the factors considered in this study. The selected factors and their corresponding ranges were determined after preliminary experiments (Table I).

Pure carbon dioxide was not sufficient to extract the investigated tropane alkaloids and it was necessary to add a polar modifier. In the case of hyoscyamine and scopolamine extractions, methanol and water with or without propylamine were investigated as modifiers. In all cases, the addition of the modifier considerably enhanced hyoscyamine and scopolamine extraction yields. However, the addition of propylamine in methanol did not improve extraction yields and numerous compounds were coextracted resulting in very complex plant extracts. In presence of water, lower extraction yields were systematically obtained. This may be due

Table I. Coded values of experimental factors.

\begin{tabular}{lcccccc}
\hline & \multicolumn{2}{c}{ Hyoscyamine } & \multicolumn{2}{c}{ Scopolamine } & \multicolumn{2}{c}{ Cocaine } \\
Level & -1 & 0 & +1 & -1 & 0 & +1 \\
\hline $\mathrm{X}_{1}$ & 10 & 20 & 30 & 15 & 20 & 25 \\
$\mathrm{X}_{2}$ & 5 & 15 & 25 & 5 & 10 & 15 \\
$\mathrm{X}_{3}$ & 40 & 70 & 100 & 40 & 70 & 100 \\
$\mathrm{X}_{4}$ & - & - & - & 10 & 20 & 30 \\
\hline $\mathrm{X}_{1}:$ Pressure (MPa) & & & & & \\
$\mathrm{X}_{2}:$ Polar modifier in $\mathrm{CO}_{2}(\% \mathrm{v} / \mathrm{v})$ & \\
$\mathrm{X}_{3}:$ Temperature $\left({ }^{\circ} \mathrm{C}\right)$ \\
$\mathrm{X}_{4}:$ Water in methanol $(\% \mathrm{v} / \mathrm{v})$
\end{tabular}

to the degradation of hyoscyamine and scopolamine in aqueous media as described in the literature [25]. Therefore, pure methanol was selected for subsequent investigations. For cocaine extraction, preliminary studies showed that the addition of water in methanol had a significant influence. Pressure, temperature, percentage of the polar modifier (mixture of $\mathrm{MeOH} / \mathrm{H}_{2} \mathrm{O}$ ) and percentage of water in methanol were investigated.

\section{Experimental design}

A central composite design was implemented in order to determine optimal conditions. In general, central composite designs need a total of $\left(2^{k}+2 k+n\right)$ runs where $k$ is the number of studied factors, $2^{k}$ are the points from the factorial design, $2 k$ the face-centred points and $n$ the number of experiments carried out at the centre. The duplication of centre point is used to estimate the experimental error. As an example, the experimental domain of three factors is shown in figure 2. In the case of hyoscyamine and scopolamine, twenty experiments were performed (Table II) while for cocaine, thirty-three experiments were carried out (Table III) [20]. All experiments were randomly performed without replication. The measured response was defined as the tropane alkaloid recovery in \% dry weight in hairy roots or leaves.

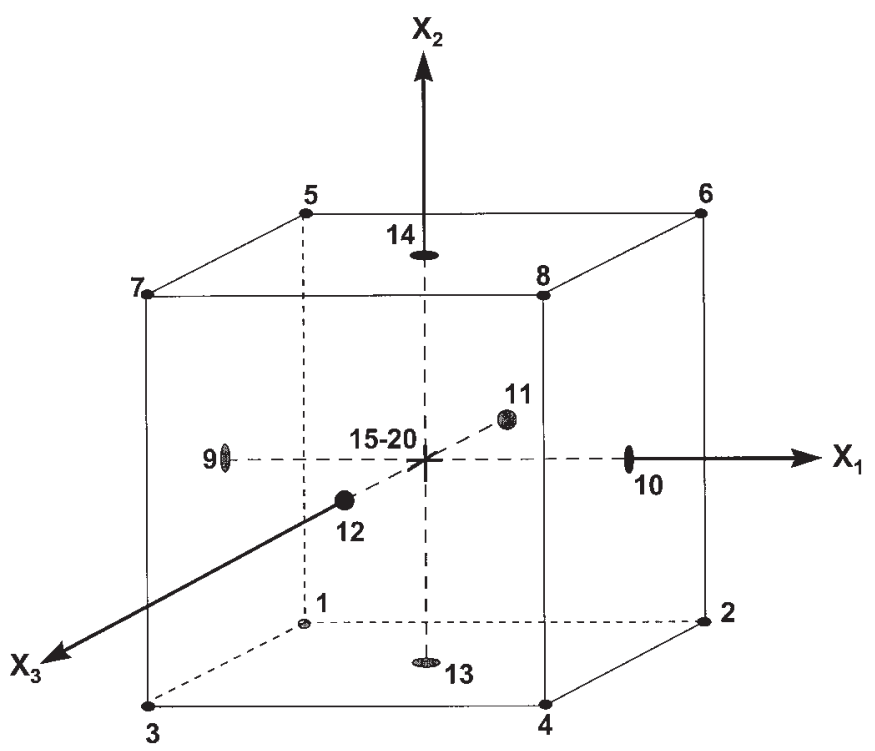

Fig 2. Schematic diagram of a face-centred central composite design for three factors.

\section{Regression modelling}

Multiple regression gives a mathematical relationship between responses and independent variables. A face-centred 
Table II. Three-factor central composite design with the corresponding responses for scopolamine and hyoscyamine extraction.

\begin{tabular}{lccccc}
\hline \multicolumn{5}{c}{ Experimental factors } & $\begin{array}{c}\text { Scopolamine } \\
\text { Trial }\end{array}$ \\
$U_{1}$ & $U_{2}$ & $U_{3}$ & dry weight & $\begin{array}{c}\text { Hyoscymine } \\
\text { \% dry weight }\end{array}$ \\
\hline 1 & 10 & 5 & 40 & 0.26 & 0.25 \\
2 & 30 & 5 & 40 & 0.04 & 0.06 \\
3 & 10 & 25 & 40 & 0.21 & 0.23 \\
4 & 30 & 25 & 40 & 0.25 & 0.32 \\
5 & 10 & 5 & 100 & 0.28 & 0.34 \\
6 & 30 & 5 & 100 & 0.06 & 0.11 \\
7 & 10 & 25 & 100 & 0.30 & 0.36 \\
8 & 30 & 25 & 100 & 0.33 & 0.39 \\
9 & 10 & 15 & 70 & 0.29 & 0.39 \\
10 & 30 & 15 & 70 & 0.18 & 0.36 \\
11 & 20 & 5 & 70 & 0.15 & 0.26 \\
12 & 20 & 25 & 70 & 0.21 & 0.36 \\
13 & 20 & 15 & 40 & 0.18 & 0.25 \\
14 & 20 & 15 & 100 & 0.28 & 0.33 \\
15 & 20 & 15 & 70 & 0.26 & 0.36 \\
16 & 20 & 15 & 70 & 0.25 & 0.40 \\
17 & 20 & 15 & 70 & 0.26 & 0.37 \\
18 & 20 & 15 & 70 & 0.21 & 0.37 \\
19 & 20 & 15 & 70 & 0.23 & 0.33 \\
20 & 20 & 15 & 70 & 0.26 & 0.32 \\
\hline
\end{tabular}

central composite design provides sufficient data to fit a second-degree expression, such as given below for three factors:

$$
\begin{gathered}
Y=b_{0}+b_{1} X_{1}+b_{2} X_{2}+b_{3} X_{3}+b_{11} X_{1}^{2}+b_{22} X_{2}^{2}+b_{33} X_{3}^{2} \\
+b_{12} X_{1} X_{2}+b_{13} X_{1} X_{3}+b_{23} X_{2} X_{3}
\end{gathered}
$$

where $Y$ represents the experimental response, $X_{i}$ the independently evaluated factors (in coded variables), $b_{0}$ the intercept and $b_{i}$ the parametric coefficients of the model obtained by multiple regression. Table IV shows the statistically significative regression parameters calculated for hyoscyamine, scopolamine and cocaine responses. It can be noted that for cocaine extraction, a cubic term $b_{124}$ had to be added to improve the modelling of the response [20].

The coefficient of determination $\left(\mathrm{R}^{2}\right)$, the adjusted coefficient of determination $\left(\mathrm{R}^{2}{ }_{\text {adj }}\right)$, the residual standard deviation $\mathrm{SD}_{\text {res }}$ were satisfactory, as shown in Table V. Moreover, the residual error values were contained within the range of $\pm 2 \mathrm{SD}_{\exp }\left(\mathrm{SD}_{\exp }\right.$, experimental standard deviation) as illustrated in figure 3 . Thus, the responses were sufficiently explained by the regression models allowing to establish response surfaces and to predict any response within the experimental domain.

From these mathematical models, the significance of the investigated factors and the interactions between them were first examined. The presence of water in methanol $\left(X_{4}\right)$ had the greatest effect on the recovery of cocaine, whereas the percentage of modifier in $\mathrm{CO}_{2}\left(X_{2}\right)$ was the most influencing factor for both scopolamine and hyoscyamine extraction.
Table III. Four-factor central composite design with the corre-

\begin{tabular}{|c|c|c|c|c|c|}
\hline \multirow[b]{2}{*}{ Trial } & \multicolumn{4}{|c|}{ Experimental factors } & \multirow{2}{*}{$\begin{array}{l}\text { Cocaine } \\
\% \text { dry weight }\end{array}$} \\
\hline & $U_{1}$ & $U_{2}$ & $U_{3}$ & $U_{4}$ & \\
\hline 1 & 15 & 5 & 40 & 10 & 0.17 \\
\hline 2 & 25 & 5 & 40 & 10 & 0.38 \\
\hline 3 & 15 & 15 & 40 & 10 & 0.43 \\
\hline 4 & 25 & 15 & 40 & 10 & 0.21 \\
\hline 5 & 15 & 5 & 100 & 10 & 0.24 \\
\hline 6 & 25 & 5 & 100 & 10 & 0.53 \\
\hline 7 & 15 & 15 & 100 & 10 & 0.54 \\
\hline 8 & 25 & 15 & 100 & 10 & 0.45 \\
\hline 9 & 15 & 5 & 40 & 30 & 0.53 \\
\hline 10 & 25 & 5 & 40 & 30 & 0.53 \\
\hline 11 & 15 & 15 & 40 & 30 & 0.54 \\
\hline 12 & 25 & 15 & 40 & 30 & 0.52 \\
\hline 13 & 15 & 5 & 100 & 30 & 0.45 \\
\hline 14 & 25 & 5 & 100 & 30 & 0.43 \\
\hline 15 & 15 & 15 & 100 & 30 & 0.55 \\
\hline 16 & 25 & 15 & 100 & 30 & 0.55 \\
\hline 17 & 15 & 10 & 70 & 20 & 0.59 \\
\hline 18 & 25 & 10 & 70 & 20 & 0.58 \\
\hline 19 & 20 & 5 & 70 & 20 & 0.55 \\
\hline 20 & 20 & 15 & 70 & 20 & 0.58 \\
\hline 21 & 20 & 10 & 40 & 20 & 0.60 \\
\hline 22 & 20 & 10 & 100 & 20 & 0.60 \\
\hline 23 & 20 & 10 & 70 & 10 & 0.57 \\
\hline 24 & 20 & 10 & 70 & 30 & 0.60 \\
\hline 25 & 20 & 10 & 70 & 20 & 0.52 \\
\hline 26 & 20 & 10 & 70 & 20 & 0.53 \\
\hline 27 & 20 & 10 & 70 & 20 & 0.51 \\
\hline 28 & 20 & 10 & 70 & 20 & 0.57 \\
\hline 29 & 20 & 10 & 70 & 20 & 0.58 \\
\hline 30 & 20 & 10 & 70 & 20 & 0.59 \\
\hline 31 & 20 & 10 & 70 & 20 & 0.50 \\
\hline 32 & 20 & 10 & 70 & 20 & 0.58 \\
\hline 33 & 20 & 10 & 70 & 20 & 0.59 \\
\hline
\end{tabular}
sponding response for cocaine extraction.

Table IV. Estimated regression coefficients of the central composite designs concerning hyoscyamine, scopolamine and cocaine extraction.

\begin{tabular}{cccc}
\hline Coefficient & Scopolamine & Hyoscyamine & Cocaine \\
\hline $\mathrm{b}_{0}$ & 0.2361 & 0.3585 & 0.5788 \\
$\mathrm{~b}_{1}$ & -0.0480 & -0.0330 & 0.0073 \\
$\mathrm{~b}_{2}$ & 0.0510 & 0.0640 & 0.0310 \\
$\mathrm{~b}_{3}$ & 0.0310 & 0.0420 & 0.0237 \\
$\mathrm{~b}_{4}$ & - & - & 0.0642 \\
$\mathrm{~b}_{11}$ & 0.0123 & 0.0164 & -0.0282 \\
$\mathrm{~b}_{22}$ & -0.0427 & -0.0486 & -0.0520 \\
$\mathrm{~b}_{33}$ & 0.0073 & -0.0686 & -0.0197 \\
$\mathrm{~b}_{44}$ & - & - & -0.0328 \\
$\mathrm{~b}_{12}$ & 0.0638 & 0.0675 & -0.0506 \\
$\mathrm{~b}_{13}$ & -0.0013 & -0.0125 & 0.0130 \\
$\mathrm{~b}_{14}$ & - & - & -0.0150 \\
$\mathrm{~b}_{23}$ & 0.0163 & 0.0075 & 0.0211 \\
$\mathrm{~b}_{24}$ & - & - & -0.0059 \\
$\mathrm{~b}_{34}$ & - & - & -0.0444 \\
$\mathrm{~b}_{124}$ & - & - & 0.0514 \\
\hline
\end{tabular}




\section{Original articles}

Table V. Statistical data.

\begin{tabular}{lccc}
\hline & Scopolamine & Hyoscyamine & Cocaine \\
\hline S.D.exp $_{\text {a) }}$ & 0.02 & 0.03 & 0.03 \\
S.D.res $^{\text {b) }}$ & 0.06 & 0.06 & 0.05 \\
$\mathrm{R}^{2}$ c) & 0.9435 & 0.9644 & 0.8950 \\
$\mathrm{R}_{\text {adj }}{ }^{\text {d) }}$ & 0.8926 & 0.9324 & 0.8024 \\
\hline
\end{tabular}

a) Experimental standard deviation in $\%(\mathrm{n}=6$ for hyoscyamine and scopolamine and $\mathrm{n}=9$ for cocaine)

b) Residual standard deviation in $\%$

c) Coefficient of determination

d) Adjusted coefficient of determination
It is noteworthy that pressure $\left(X_{1}\right)$ had no effect on cocaine recovery while this factor slightly influenced scopolamine and hyoscyamine extraction probably due to a larger experimental domain. However, the pressure associated to the percentage of modifier in $\mathrm{CO}_{2}\left(b_{12}\right)$ showed to have a strong influence in the extraction of the three tropane alkaloids. Moreover, for cocaine extraction, a second first-order interaction $b_{34}$ between the temperature and the percentage of water in methanol, revealed to be important, along with a second-order interaction $b_{124}$.

Optimal conditions for SFE of alkaloids were also determined from mathematical models using LUMIERE software package [5]. The prediction quality of the models was experimentally verified by the good agreement between the experimental and the predicted responses, as shown in Table VI. Furthermore, it has to be noted that extracted amounts were in good agreement with values reported in the literature for cocaine [24, 26-28] as well as for hyoscyamine and scopolamine [23]. Moreover, standard deviations obtained by SFE were comparable to those obtained by liquid-solid extraction.

\section{Analysis of the response surfaces}

Response surfaces can be illustrated as three-dimensional plots by presenting the response in function of two factors and keeping the others constant. Thus, it is possible to visualise the alkaloid extraction in relation to pressure, temperature and polar modifier concentration within the experimental domain.

Figure $4 \mathrm{a}$ and figure $4 \mathrm{~b}$ show the methanol percentage effect on the extraction yield, in relation with the pressure, at a fixed temperature set at its optimum value, $75^{\circ} \mathrm{C}$ and $78{ }^{\circ} \mathrm{C}$, for scopolamine and hyoscyamine, respectively. Response surfaces were surprisingly very different. Indeed, for scopolamine, which is the most polar compound, the extraction yield increased with a higher methanol percentage, independently of the pressure. On the other hand, hyoscyamine response surface shows an optimum around $17 \%(\mathrm{v} / \mathrm{v}) \mathrm{MeOH}$. Furthermore, the pressure had no significant influence on the extraction at any methanol percentage.
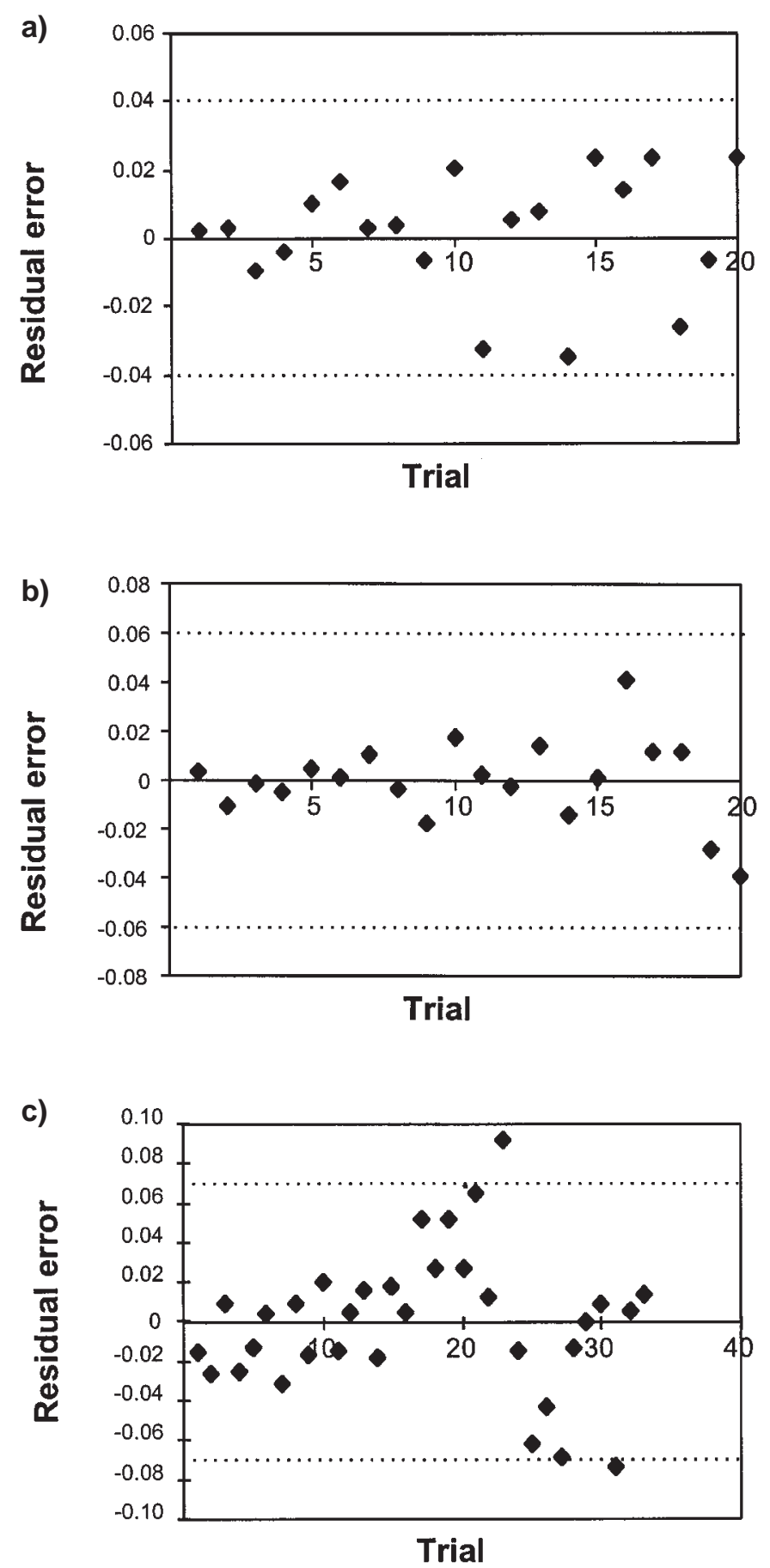

Fig 3. Residual error for a) scopolamine, b) hyoscyamine and c) cocaine.

For cocaine extraction, response surfaces of the two most important interactions (i.e. pressure and modifier percentage in $\mathrm{CO}_{2}$, and temperature and water percentage in methanol) are reported in figure 5. As shown in figure 5a, the cocaine response surface shows a fairly strong degree of curvature 


\section{Original articles}
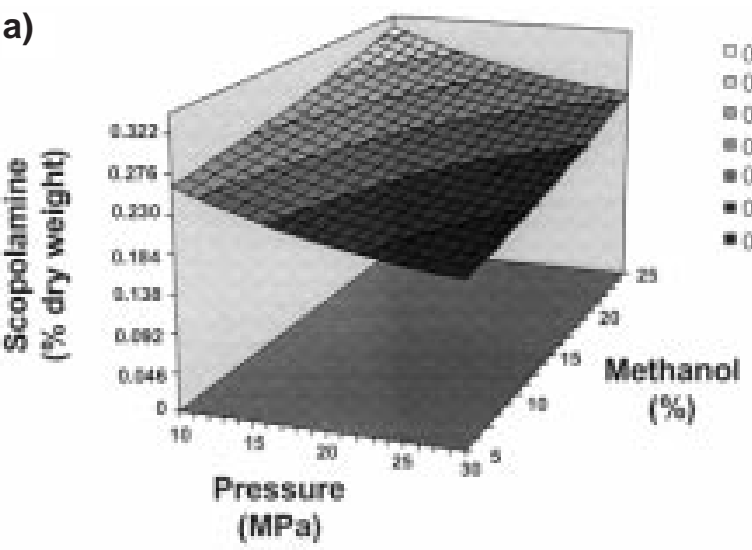

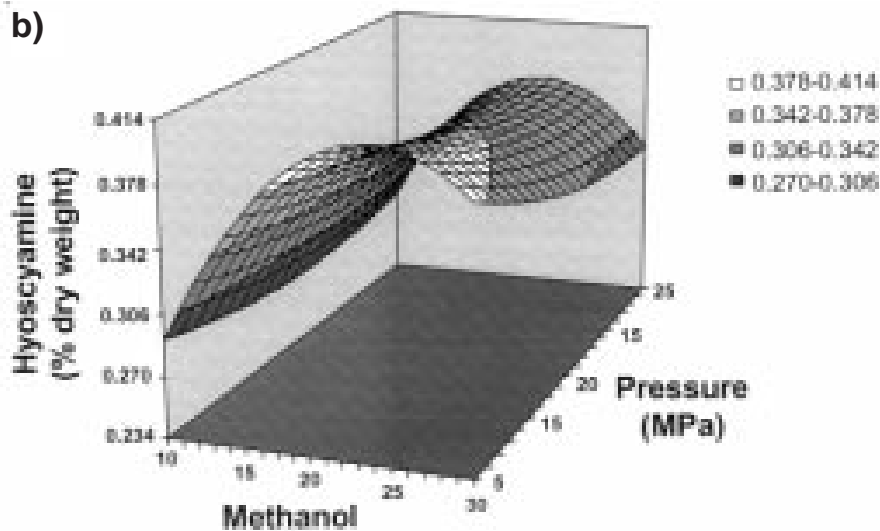

$(\%)$

Fig 4. Response surface plots for a) scopolamine at $75^{\circ} \mathrm{C}$ and for b) hyoscyamine at $78^{\circ} \mathrm{C}$.
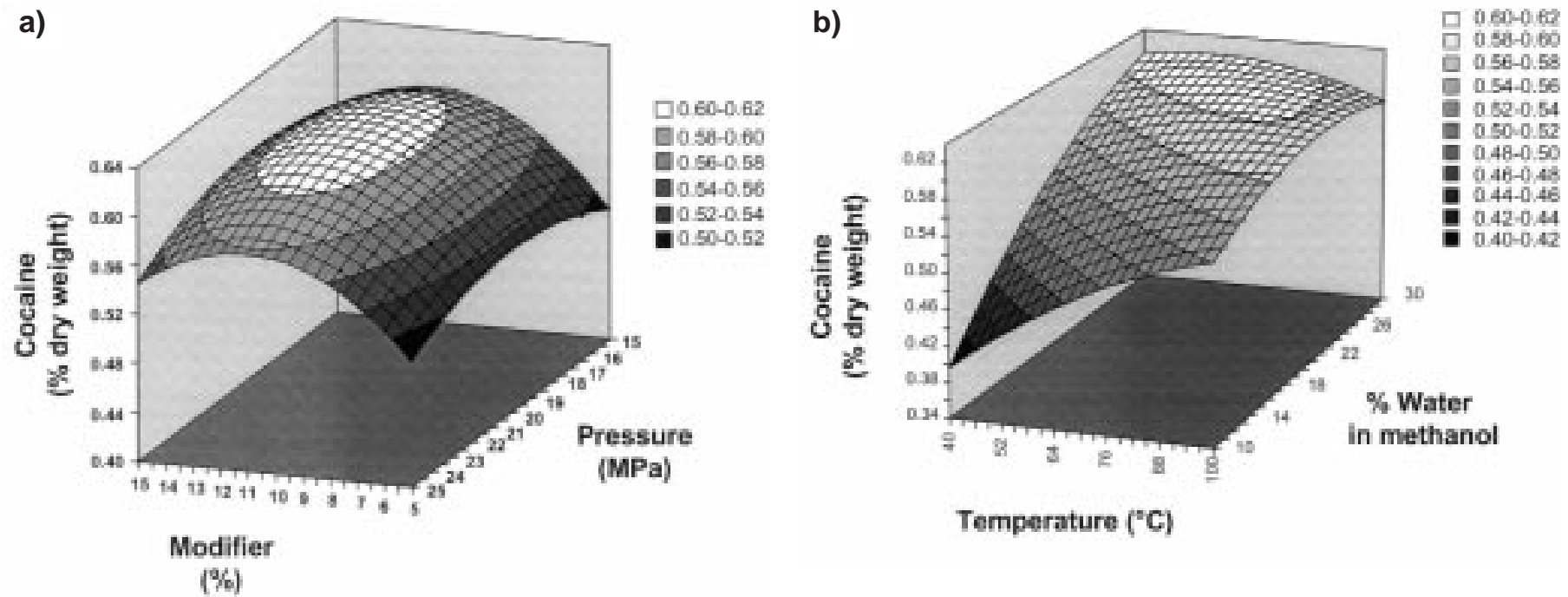

Temperature ("C)

Fig 5. Response surface plots for cocaine a) at $70{ }^{\circ} \mathrm{C}$ and with $29 \%$ of water in methanol and b) at $19.4 \mathrm{MPa}$ and with $11.33 \%$ of modifier in $\mathrm{CO}_{2}$.

where the optimum can be readily determined. Pressure had a weak influence on cocaine recovery which confirmed the little importance of this factor. Figure $5 \mathrm{~b}$ demonstrated the importance of the percentage of water in methanol on cocaine extraction. Moreover, at high water content (i.e. > $24 \% \mathrm{v} / \mathrm{v}$ ) the cocaine recovery reached a plateau independently of temperature.

The influence of pressure and temperature on extraction yields is fairly identical for hyoscyamine and scopolamine and the response surface of the latter only is discussed (Fig. 6). According to figure $4 \mathrm{~b}$, methanol percentage was set at $20 \%(\mathrm{v} / \mathrm{v})$. At high pressure, increasing the extraction temperature from $40{ }^{\circ} \mathrm{C}$ to $100{ }^{\circ} \mathrm{C}$ yielded significant increases in hyoscyamine and scopolamine recoveries, despite the $\mathrm{CO}_{2}$ density decrease. At low pressure, the effect of temperature is less pronounced. These results confirm that SFE is governed by the volatility of analytes as well as by the fluid density [12]. In order to extract hyoscyamine and scopolamine simultaneously, a compromise was made: the most favourable extraction conditions for both compounds are reported in table VI.

For cocaine extraction, the optimal zone was perfectly defined and showed a good robustness of the extraction method (Fig. 5a), whereas the optimal conditions for both hyoscyamine and scopolamine are situated along a ridge (Fig. 4b and Fig. 6) and indicate a poor robustness of the extraction method. 


\section{Original articles}

Table VI. Comparison of predicted and measured values. Optimal conditions (A) : $\mathrm{P}=15 \mathrm{MPa}, \mathrm{T}=85{ }^{\circ} \mathrm{C}, 20 \% \mathrm{MeOH}$; (B) $: \mathrm{P}=19.4 \mathrm{MPa}, \mathrm{T}=70{ }^{\circ} \mathrm{C}, 11.33 \%$ of polar modifier, $29 \%$ of water in methanol.

\begin{tabular}{|c|c|c|c|c|c|}
\hline & Conditions & $\begin{array}{c}\text { Predicted } \\
\% \text { dry weight }\end{array}$ & $\begin{array}{c}\text { Measured } \\
\% \text { dry weight a) }\end{array}$ & $S . D_{\text {exp }}^{b)}$ & $\begin{array}{c}\text { Literature } \\
\% \text { dry weight }\end{array}$ \\
\hline Scopolamine & A & 0.28 & 0.25 & 0.02 & 0.23 \\
\hline Hyoscyamine & A & 0.39 & 0.37 & 0.03 & 0.36 \\
\hline Cocaine & $\mathrm{B}$ & 0.61 & 0.60 & 0.04 & 0.60 \\
\hline
\end{tabular}

a) Mean of triplicate

b) Experimental standard deviation in $\%$ ( $n=6$ for hyoscyamine and scopolamine and $n=9$ for cocaine)

c) Values reported in the literature for liquid-solid extractions of cocaine [24, 26-28] and of hyoscyamine and scopolamine [22]

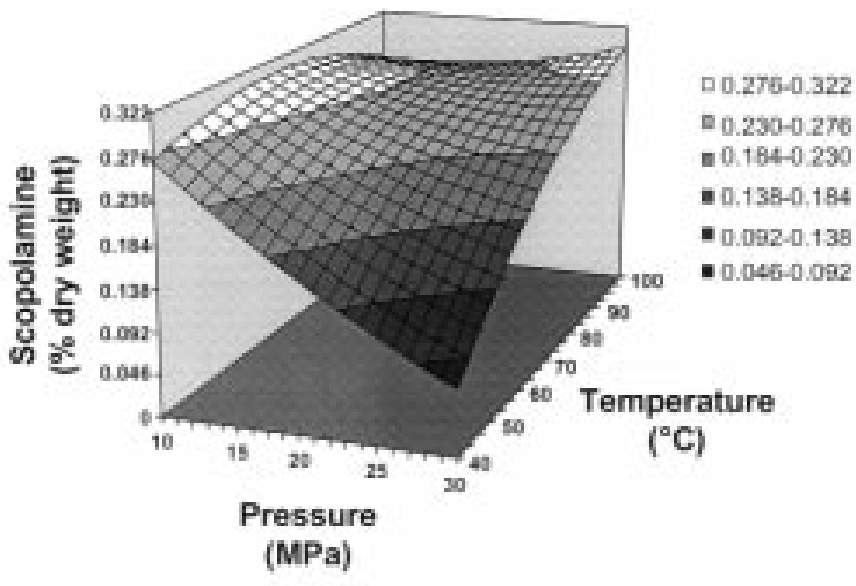

Fig 6. Response surface plots for scopolamine with $20 \% \mathrm{MeOH}$.

\section{Conclusion}

In this paper, SFE was demonstrated to be a valuable alternative technique to classical extraction methods for the tropane alkaloids studied.

Central composite designs were used to estimate the main and synergic effects of the supercritical fluid extraction factors on hyoscyamine, scopolamine and cocaine recoveries, as well as to determine optimal conditions. Pressure, temperature, the nature and percentage of the polar modifier were investigated and their influence on extraction recoveries evaluated. The methanol percentage revealed to be the most influencing factor in hyoscyamine and scopolamine extraction, while the water content in methanol was the predominant factor in cocaine extraction. Response surfaces were also drawn from the regression models in order to visualise the robustness of the extraction methods. The experimental results were in good agreement with those predicted by the models. Experimental designs afford maximum information about supercritical fluid extraction in less experiments than a univariate development would have required.

\section{Acknowledgements}

We acknowledge Dr. Marcel Caude and collaborators from the ESPCI (Paris, France) for their collaboration and fruitful discussions about supercritical fluid extraction.

\section{References}

1. Box, G. E. P.; Wilson, K. B. J. R. Stat. Soc. 1951, Ser. B. 13, $1-45$.

2. Plackett, R. C.; Burman, J. P. Biometrika 1946, 33, 305-325.

3. Doelhert, D. H. Appl. Stat. 1970, 231-239.

4. NEMROD software package (LPRAI, Marseille, France).

5. LUMIERE software package (SIER, Enghien-les-Bains, France).

6. Lantéri, P.; Longeray, R. Analusis 1996, 24, M 17-M 27.

7. Goodman and Gilman's, The Pharmacological Basis of Therapeutics; J.G. Hardman, A.G. Gilman, L.E. Limbird, Ed.; New York, St Louis ; 1995; $8^{\text {th }}$ Ed ; pp 141-160.

8. Cone, E. J. J. Anal. Toxicol. 1995, 19, 459-478.

9. Castioni, P.; Christen, P.; Veuthey J.-L. Analusis 1997, 25, 8196.

10. Modey, W. K.; Mulholland, D. A.; Raynor, M. W. Phytochem. Anal. 1996, 7, 1-15.

11. Chaudot, X.; Tambuté, A.; Caude, M. Analusis 1997, 25, 8196.

12. Supercritical Fluid Extraction and Its Use in Chromatographic Sample Preparation; Westwood, S.A., Ed.; Blackie, Glasgow; 1993.

13. Reynor, M. W.; Davis, J. L.; Bartle, K. D.; Clifford, A. A.; Williams, A.; Chalmer, J. M.; Cook, B. W. J. High Resolut. Chromatogr. Commun. 1988, 11, 766-775.

14. Reikkola, M. L.; Manninen, P.; Hartonen, K. In SFE, SFE/GC and SFE/SFC : Instrumentation and applications, In Hyphenated Techniques in Supercritical Fluid Chromatography and Extraction; K. Jinno, Ed.; Amsterdam ; 1992; Vol.53; pp. 275-304.

15. Later, D. W.; Richter, B. E.; Knowles, D. E.; Andersen, M. R. J. Chromatogr. Sci. 1986, 24, 249-253.

16. Crowther, J. B.; Henion, J. D. Anal. Chem. 1985, 57, 27112716.

17. Veuthey, J-L.; Edder, P.; Staub, C. Analusis 1995, 23, 258-265.

18. Morrison, J. F.; Chesler, S. N.;. Yoo, W. J.; Selavka, C. M. Anal. Chem. 1998, 70, 163-172. 


\section{Original articles}

19. Stahl, E.; Willing, E. Planta Med. 1978, 34, 192-202.

20. Brachet, A.; Christen, P.; Gauvrit, J.-Y.; Longeray, R.; Lantéri, P.; Veuthey, J.-L. J. Biomed. Biophys. Meth., in press.

21. Mateus, L.; Cherkaoui, S.; Christen, P.; Veuthey, J-L. J. Chromatogr. A 1998, 829, 317-325.

22. Nussbaumer, P.; Kapétanidis, I.; Christen, P. Plant Cell Rep. 1998, 17, 405-409.

23. Mateus, L.; Cherkaoui, S.; Christen, P.; Veuthey, J-L. Curr. Topics Phytochem., in press.
24. Turner, C. E.; Ma, C. Y.; ElSohly, M. A. Bull. Narcotics 1979, 31, 71-76.

25. Smithuis, L. O. M. J. Pharm. Weekbl. 1969, 104, 1097-1120.

26. Moore, J. M.; Casale, J. F.; Klein, R. F. X.; Cooper, D. A.; Lydon, J. J. Chromatogr. A 1994, 659, 163-175.

27. US Drug Enforcement Administration, 1993, unpublished results.

28. Plowman, T.; Rivier, L. Ann. Bot. 1983, 51, 641-659. 